\title{
Avaliação de manifestações patológicas em pilares de edificação multifamiliar localizado em ambiente agresivo.
}

\author{
L. Onghero ${ }^{1,2 *}$, J. Stocco ${ }^{3}$ \\ *Autor de Contato: lucasjba@gmail.com \\ ${ }^{1}$ Departamento de Engenharia Civil, Universidade Federal de Santa Catarina, Florianópolis, Brasil. \\ ${ }^{2}$ Departamento de Engenharia Civil, Universidade do Contestado, Concórdia, Brasil. \\ ${ }^{3}$ Stocco Engenheiros Associados, Florianópolis, Brasil.
}

\begin{abstract}
RESUMO
As estruturas de concreto armado eram consideradas intrinsecamente duráveis, imunes à degradação, mesmo que sua execução seja realizada sem o devido cuidado e estejam expostas a ambientes agressivos. Nesse contexto, é apresentado a avaliação dos Pilares de uma edificação construídas em concreto armado, apresentando os efeitos da ação do ambiente agressivo, juntamente com a falta de manutenção periódica. A edificação objeto do estudo localiza-se na cidade de Florianópolis -SC. O condomínio encontra-se a na proximidade do mar, condomínio residencial multifamiliar, construído com sistema de elementos estruturais em concreto armado e alvenaria de vedação para a sua construção, possuindo 27 anos a contar do início da edificação. Após as análises, percebe-se que mais da metade dos elementos vistoriados apresentam degradação da estrutura em virtude da corrosão da armadura, de forma já visível através da sua fissuração. A classificação GUT mostrou que cerca de $15 \%$ dos pilares são classificados como GUT 4 e 5, apresentando estado de degradação grave/gravíssimo. Verificou-se que as manifestações são resultantes em falha de detalhamento oiu existência de projeto, falta de cuidados durante a escolha dos materiais e técnica construtiva aplicada, além da inexistência de manuais indicando o devido procedimento para a realização da manutenção da edificação.
\end{abstract}

Palabras clave: Patologia; Corrosão de armadura; Manutenção predial; GUT; Agressividade ambiental. 


\section{INTRODUÇÃO}

As estruturas de concreto armado eram consideradas intrinsecamente duráveis, imunes à degradação, mesmo que sua execução seja realizada sem o devido cuidado e estejam expostas a ambientes agressivos. A partir dos anos 80, o crescente número de estruturas degradadas, apresentando riscos de segurança e elevados custos de manutenção mudou a perspectiva, passando a compreender a importância de prevenir a degradação do concreto e principalmente, a corrosão das armaduras. (Bertolini, 2000)

Um estudo realizado pelo IBAPE-SP (2015), apontou que $66 \%$ das prováveis causas e origens dos acidentes provocados pela presença de manifestações patológicas estão relacionados à deficiência e inexistência de manutenção predial. A prática da realização de inspeções periódicas nas edificações e da manutenção preventiva, reduz a ocorrência de acidentes e é indispensável para garantir que se atinja a vida útil mínima das edificações (ALVES, 2009).

Segundo Oliveira (2013), as inspeções devem ser realizadas por profissionais habilitados, sendo capazes de transmitir as informações técnicas necessárias para cada caso e realizar as inspeções de forma segura, minimizando os riscos de acidentes de trabalho. Em contrapartida, as inspeções físicas geralmente não são realizadas por profissionais habilitados na área de Patologia, transformando a inspeção em uma avaliação e resultando em diagnósticos imprecisos.

A ação do ambiente nas estruturas de concreto armado pode determinar um dano progressivo no elemento estrutural, tanto no concreto quanto nas armaduras. Essa ação pode ser de tipo Físico, químico, biológico ou mecânico. Dependendo o tipo de degradação que ocorre, é possível determinar qual dos materiais (pasta de cimento ou armadura) apresentam primeiramente a degradação, e como como efeito secundário, afeta os demais constituintes do elemento. (Bertolini, 2010).

Ressalta-se que os mecanismos de degradação podem atuar de maneira sinérgica e, não há uma única causa para a ocorrência da degradação do concreto. Dentro dessa perspectiva, pode-se destacar que com exceção das causas mecânicas, todas as outras formas de degradação envolvem transporte de fluidos. (Neville, 2016)

A prevenção de degradação de estruturas de concreto armado podem dever-se iniciar no momento de projeto da obra, onde segundo as diretrizes da NBR 6118, onde há requisitos para garantir a durabilidade mínima da edificação de acordo com a localização em que vai ser construída, de maneira que sua vida útil seja garantida.

\section{ESTUDO DE CASO}

A edificação objeto do estudo localiza-se na cidade de Florianópolis -SC. A escolha do empreendimento ocorreu devido à demanda de parte do condomínio por uma avaliação mais criteriosa a respeito da degradação que os elementos vêm sofrendo ao longo do tempo.

O condomínio encontra-se a na proximidade do mar, conforme pode ser observado na Figura 1. Trata-se de um condomínio residencial multifamiliar, apresentando $15.299 \mathrm{~m}^{2}$ de área construída e $17.581 \mathrm{~m}^{2}$ de área total, sendo utilizado sistema de elementos estruturais em concreto armado e alvenaria de vedação para a sua construção.

Figura 1 - Localização das edificações avaliadas. 


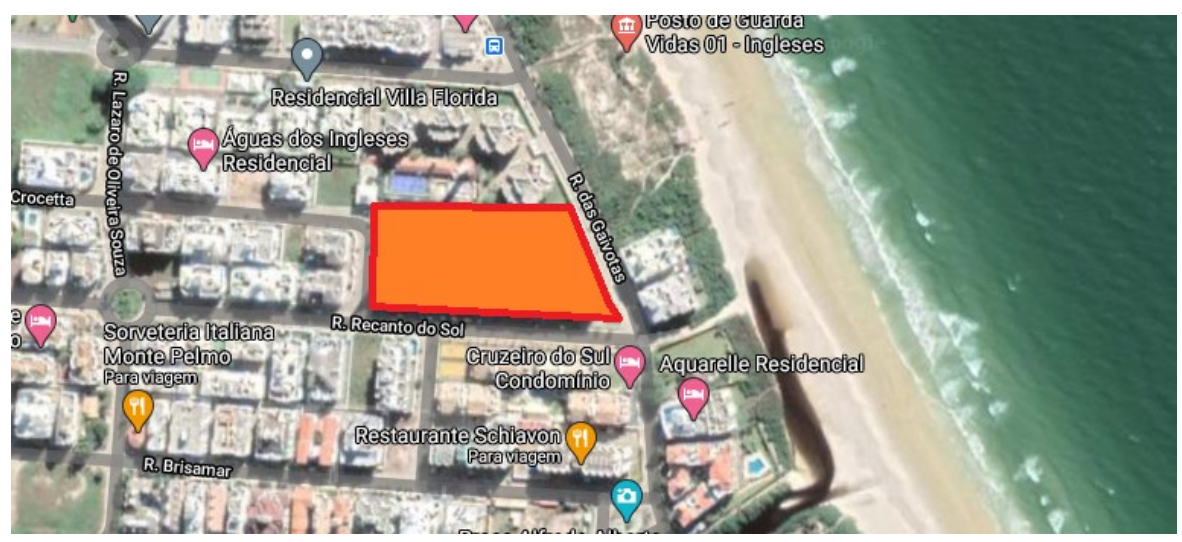

De acordo com os dados levantados, as edificações começaram a ser construídas em 1994, sendo assim, possuem na presenta data possuem 27 anos do início da construção e o início da ocupação se deu a partir de janeiro de 2000. Trata-se de um condomínio multifamiliar onde o sistema construtivo utilizado é de elementos estruturais em concreto armado e alvenaria de vedação, contendo: 05 (cinco) Blocos (A,B,C,D,E), cada bloco possui 03 (três) andares e 19 (dezenove) apartamentos por bloco.

\section{PROCEDIMENTO}

A degradação do concreto armado é um processo que ocorre ao longo da vida útil da edificação. Portanto é nítido a necessidade de um plano e gerenciamento de manutenção da estrutura, prevenindo assim que a degradação atinja níveis críticos, não colocando em riscos os usuários e resultando em menor custo para o reparo. Nesse aspecto, a Associação Brasileira de Normas Técnicas (ABNT) apresenta um conjunto de normas destinado à manutenção predial: NBR 15575 - Norma de desempenho da edificação; NBR 14037 - Manual de uso, operação e manutenção; NBR 5674 - Gestão da manutenção; NBR 16280 - Gestão das reformas; CE-02 - Inspeção predial. $\mathrm{Na}$ realização dos trabalhos foram seguidas as recomendações normativas da NBR 16747 Inspeção Predial - Diretrizes, conceitos, terminologia e procedimento (ABNT, 2020).

Realizou-se uma vistoria no local, utilizando os sentidos humanos e instrumentos, em conjunto da anamnese para a obtenção de informações orais e formalizadas. A metodologia utilizada foi baseada na sequência exposta no quadro 1.

Quadro 1. Sequência de procedimento metodológico utilizado.

\begin{tabular}{|c|l|l|}
\hline 1 & Vistoria & Constatação no local, predominantemente sensorial. \\
\hline 2 & Anamnese & $\begin{array}{l}\text { Entrevista realizada com os envolvidos, para coleta de } \\
\text { dados e obtenção de informações sobre o histórico }\end{array}$ \\
\hline 3 & $\begin{array}{l}\text { Exames } \\
\text { Complementares }\end{array}$ & Ensaios no local (destrutivos e não destrutivos) \\
\hline 4 & Pesquisa & Bibliográfica, tecnológica ou científica. \\
\hline
\end{tabular}




\begin{tabular}{|l|l|l|}
\hline 5 & Diagnóstico & $\begin{array}{l}\text { Origens, } \\
\text { causas e } \\
\text { mecanismos de ocorrência. }\end{array}$ \\
\hline 6 & Definição de conduta & $\begin{array}{l}\text { Orientação de serviços e materiais para a recuperação do } \\
\text { sistema. }\end{array}$ \\
\hline
\end{tabular}

Fonte: NBR 16747, 2020

De acordo com a norma de inspeção predial disponibilizada pelo IBAPE, a inspeção pode ser classificada de acordo com a complexidade e elaboração do laudo, levando em consideração as características técnicas da edificação, manutenção e operação existentes, sendo a inspeção classificada em nível 1, nível 2 ou nível 3. A classificação da inspeção é realizada pelo inspetor predial, após análises das características dela.

Dentro desse contexto, a edificação avaliada nessa ocasião pode ser classificada como Inspeção de Nível 02, uma vez que essa se caracteriza como edificações de média complexidade técnica, de manutenção e operação de seus elementos e sistemas construtivos, de padrões médios e com sistemas convencionais. Além de apresentar como característica possuir vários pavimentos, sem plano de manutenção.

As manifestações encontradas recebem sua classificação quanto as anomalias apresentadas e a origem de suas falhas. A metodologia utilizada é embasado no trabalho desenvolvido por Boes (2017), onde faz uma integração entre as diretrizes de avaliação e organiza as anomalias quanto a priorização de reparo a ser desenvolvido na estrutura. As classificações empregadas na metodologia está resumida no quadro 02 .

Quadro 2. Classificação das anomalias e falhas.

\begin{tabular}{|c|c|c|}
\hline \multirow{5}{*}{ 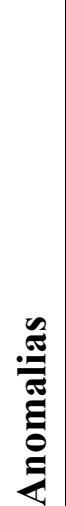 } & Classificação & Descrição \\
\hline & Endógena & $\begin{array}{l}\text { Originarias da própria edificação, geralmente causada por } \\
\text { erros de projetos, defeitos de construção ou fabricação ou } \\
\text { emprego de materiais não especificados }\end{array}$ \\
\hline & Exógena & $\begin{array}{l}\text { Oriundos de fatores externos a edificação, causadas pela ação } \\
\text { de terceiros }\end{array}$ \\
\hline & Natural & Ocorrem por fenômenos da natureza \\
\hline & Funcional & $\begin{array}{l}\text { Originadas da degradação de sistemas construtivos pelo } \\
\text { envelhecimento natural e, consequentemente, térmico da vida } \\
\text { útil e por falhas de usou e/ou manutenção }\end{array}$ \\
\hline \multirow[b]{3}{*}{ 胥 } & Planejamento & $\begin{array}{l}\text { Falhas de procedimentos e especificações inadequados do } \\
\text { plano de manutenção, sem aderência a questões técnicas, de } \\
\text { uso de operação, de exposição ambiental e, principalmente, de } \\
\text { confiabilidade e disponibilidade das instalações, consoante a } \\
\text { estratégia de manutenção. Além dos aspectos de concepção do } \\
\text { plano, há falhas relacionadas as periodicidades de execução. }\end{array}$ \\
\hline & Execução & $\begin{array}{l}\text { Associada à manutenção proveniente de falhas causadas pela } \\
\text { execução inadequada de procedimentos e atividades do plano } \\
\text { de manutenção, incluindo o uso inadequado dos materiais }\end{array}$ \\
\hline & Operacional & $\begin{array}{l}\text { São relativas aos procedimentos inadequados de registros, } \\
\text { controles rondas e demais atividades pertinentes }\end{array}$ \\
\hline
\end{tabular}




\begin{tabular}{|l|l|l|l|}
\hline & $\begin{array}{l}\text { Deriva da falta de controle de qualidade de qualidade dos } \\
\text { serviços de manutenção, bem como a a falta de } \\
\text { acompanhamento dela }\end{array}$ \\
\hline
\end{tabular}

Fonte: Boes, 2017.

Tendo em conta as recomendações apresentadas pelo inspetor predial, deve haver a organização das prioridades em patamares de urgência. Na avaliação do Grau de Risco foi utilizado o método GUT (Gravidade/Urgência/Tendência). O quadro 03 apresenta o método GUT aplicado a inspeção predial.

Quadro 3. Método GUT de inspeção predial

\begin{tabular}{|c|c|c|c|c|}
\hline Valor & Gravidade & Urgência & Tendência & GUT \\
\hline 1 & $\begin{array}{l}\text { Nenhum risco à saúde, integridade física dos } \\
\text { usuários, ao meio ambiente ou ao edifício. } \\
\text { Mínima depreciação do patrimônio. } \\
\text { Eventuais trocas de componentes, sem } \\
\text { comprometimento imobiliário }\end{array}$ & Não tem pressa & Não vai piorar & Baixo \\
\hline 2 & $\begin{array}{l}\text { Sem risco à integridade física dos usuários, } \\
\text { sem risco ao meio ambiente, pequenos } \\
\text { incômodos estéticos ou de utilização, } \\
\text { pequenas substituições de componentes ou } \\
\text { sistemas, reparos de manutenção planejada } \\
\text { para recuperação ou prolongamento de vida } \\
\text { útil. Prejuízo financeiro pequeno. }\end{array}$ & $\begin{array}{l}\text { Pode Esperar } \\
\text { um pouco }\end{array}$ & $\begin{array}{l}\text { Vai piorar a } \\
\text { longo prazo }\end{array}$ & Baixo \\
\hline 3 & $\begin{array}{l}\text { Risco à saúde dos usuários, desconfortos na } \\
\text { utilização dos sistemas, deterioração passível } \\
\text { de restauração/reparo, podendo provocar } \\
\text { perda de funcionalidade com prejuízo à } \\
\text { operação direta de sistemas ou componentes. } \\
\text { Danos ao meio ambiente passíveis de reparo. } \\
\text { Prejuízo financeiro médio. }\end{array}$ & $\begin{array}{l}\text { O mais cedo } \\
\text { possível }\end{array}$ & $\begin{array}{l}\text { Vai piorar a } \\
\text { médio prazo }\end{array}$ & Médio \\
\hline 4 & $\begin{array}{l}\text { Risco de ferimentos aos usuários, danos } \\
\text { reversíveis ao meio ambiente ou ao edifício. } \\
\text { Impacto recuperável com o } \\
\text { comprometimento parcial do desempenho e } \\
\text { funcionalidade (vida útil) do sistema que } \\
\text { afeta parcialmente a saúde dos usuários ou o } \\
\text { meio ambiente. Prejuízo financeiro alto. }\end{array}$ & Urgente & $\begin{array}{l}\text { Vai piorar em } \\
\text { pouco tempo }\end{array}$ & Crítico \\
\hline 5 & $\begin{array}{l}\text { Risco de morte, risco de } \\
\text { desabamento/colapso pontual ou } \\
\text { generalizado, iminência de Incêndio, impacto } \\
\text { irrecuperável com perda excessiva do } \\
\text { desempenho e funcionalidade, } \\
\text { comprometimento irrecuperável da vida útil } \\
\text { do sistema causando danos grave à saúde dos } \\
\text { usuários ou ao meio ambiente. Prejuízo } \\
\text { financeiro muito algo. }\end{array}$ & Ação Imediata & $\begin{array}{l}\text { Vai piorar } \\
\text { imediatamente }\end{array}$ & Crítico \\
\hline
\end{tabular}

Fonte: Boes, 2017. 


\subsection{Equipamentos utilizados}

A câmera termográfica utilizada na realização dos ensaios não destrutivos foi a FLIR C2 número I5-44820, com aprimoramentos de imagem MSX através da adição de detalhes da câmera de luz visível a imagem de infravermelho em tempo real.

As imagens termográficas receberam tratamento para melhor visualização e emissão de relatório através de software com interface digital disponibilizado pela FLIR Systems, Inc.

A Pacometria é um ensaio não destrutivo usado para determinar a posição das armaduras e, dependendo do equipamento utilizado para o ensaio, pode ser possível descobrir o cobrimento de concreto em peças de concreto armado. Este permite estimar sua dimensão, cobrimento e orientação, sendo útil na realização de vistorias em elementos estruturais e edifício, principalmente quando não há documentação disponível.

Basicamente, o ensaio tem por finalidade detectar materiais construtivos não visíveis, que estão no interior de paredes e elementos estruturais. Usualmente é utilizado para detectar barras de aço, no entanto, alguns modelos podem detectar: tubulações hidráulicas de PVC, fiações elétricas, madeira e tubos de cobre.

O ensaio de pacometria é fundamental para a realização de outros ensaios, tais como: profundidade de carbonatação, extração de testemunho e potencial de corrosão.

Para o ensaio de pacometria, utiliza-se um equipamento eletrônico chamado pacômetro, que funciona por indução magnética. Primeiramente, deve-se posicionar o equipamento no elemento estrutural ou na parede a ser avaliada e movimentá-lo no sentindo horizontal e vertical, observando sempre as informações presentes na tela do equipamento.

O ensaio de esclerometria é um tipo de ensaio não destrutivo, e consiste em um método utilizado para determinar a dureza superficial do concreto endurecido, assim como é possível determinar a uniformidade do concreto utilizado em uma mesma edificação.

A realização do ensaio de esclerometria é feita com uma massa martelo que se choca com a área que está sendo submetida ao teste. Para isso, essa massa martelo recebe o impulso de uma mola. Dessa forma, quanto maior for a dureza da superfície, menor será a deformação permanente, assim como também será menor a reflexão da massa martelo, ou o seu recuo.

É necessário esclarecer que esta técnica não determina a resistência do concreto, apesar de muitos profissionais a utilizarem para esse fim. Caso queira determinar a resistência do concreto através da esclerometria, é necessário, para todo local a ser analisado, construir uma curva de correlação entre as leituras obtidas no esclerômetro e a resistência do concreto encontrado no local da análise. Portanto, torna-se mais confiável e menos custoso realizar a extração para esse fim, utilizando a esclerometria como teste para definição dos pontos a serem extraídos.

Figura 2. Modelo dos equipamentos utilizados durante a inspeção, câmera termográfica (a), Pacômetro (b) e esclerômetro (c).
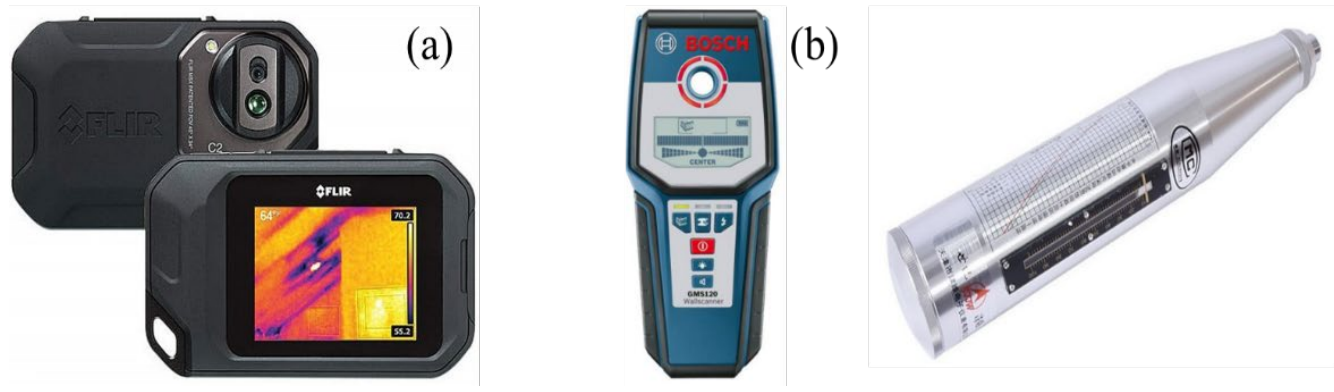

(c) 


\section{APRESENTAÇÃO E ANÁLISE DOS RESULTADOS}

Previamente foi requisitado ao síndico uma lista de documentos para serem organizados e se possível disponibilizados, facilitando a organização do plano de ação a ser executado, além de obter maiores informações da edificação, como materiais, técnicas e processo construtivo utilizado. No quadro 04 é apresentado a relação de documentos solicitados, avaliando-os em disponível ou não, assim como mostrando algumas observações a respeito da solicitação.

Quadro 4. Relação de documentos.

\begin{tabular}{|c|c|c|}
\hline Documentação Solicitada & Disponível & Observações \\
\hline Habite-se & Sim & Apta a partir de 15/06/2011 \\
\hline Memorial Descritivo & Não & Não localizado \\
\hline $\begin{array}{l}\text { Manual de uso, operação e } \\
\text { manutenção (ABNT NBR } \\
\text { 14037:2011 versão } \\
\text { corrigida 2014) }\end{array}$ & Não & Não existe \\
\hline $\begin{array}{l}\text { Programa de Gestão de } \\
\text { Manutenção (ABNT NBR } \\
\text { 5674:2012) }\end{array}$ & Não & Não existe \\
\hline Projeto Arquitetônico & Não & $\begin{array}{l}\text { Localizado apenas uma planta de um pavimento } \\
\text { tipo } 03 / 10 \text {. Localizado } 08 \text { folhas } 3^{\mathrm{a}} \text { versão. }\end{array}$ \\
\hline Projeto Estrutural & Não & Entregue somente uma planta de formas \\
\hline Projeto Elétrico & Não & $\begin{array}{l}\text { O projeto elétrico disponibilizado corresponde } \\
\text { somente a piscina, quadras e salão de festas }\end{array}$ \\
\hline Projeto Hidrossanitário & Não & $\begin{array}{l}\text { Somente da parte comum executada mais } \\
\text { recentemente }\end{array}$ \\
\hline $\begin{array}{l}\text { Projeto } \quad \text { Preventivo } \\
\text { Incêndio }\end{array}$ & Não & Não apresentado \\
\hline Projeto Cobertura & Não & Não apresentado \\
\hline Projeto Impermeabilização & Não & Não apresentado \\
\hline
\end{tabular}

Durante a anamnese várias informações foram obtidas destacando-se:

$\checkmark$ O projeto do empreendimento teve se início em 1994, após o início das obras a construtora 
faliu e a continuidade dos trabalhos ocorreu através da organização de um grupo de compradores.

$\checkmark$ A ocupação do condomínio teve início em janeiro de 2000 com o Habite-se expedido em junho de 2011. Por várias circunstâncias, teve-se que refazer os projetos arquitetónico, preventivo contra incêndio e hidrossanitário, além de adequar a construção às exigências da legislação atual para a obtenção do Habite-se.

$\checkmark$ A primeira intervenção estrutural ocorreu em 2016 num total de 110 pilares do pavimento térreo que apresentavam deterioração visível. A execução foi feita pela Fênix Engenharia não tendo sido documentada. Outros 70 pilares tiveram intervenção com mão de obra própria do condomínio. Nas vigas aparentes foram feitos paliativos com a aplicação da argamassa.

$\checkmark$ Através de informação não documental inicialmente foi informado que todo o concreto utilizado na estrutura havia sido feito na própria obra. Posteriormente foi informado que o concreto havia sido fornecido por concreteira, então solicitou-se documentação comprobatória tal como notas fiscais ou laudos de resistência de corpos de prova, até momento da redação desse parecer não havia sido localizada ainda a documentação.

Em seguida realizou-se uma visita aos pavimentos garagem de todos os blocos observando-se trincas e fissuras em pilares e vigas, características de expansão de armadura por corrosão (Figura 2).

Figura 3. Pilares com indicações de corrosão de armadura.
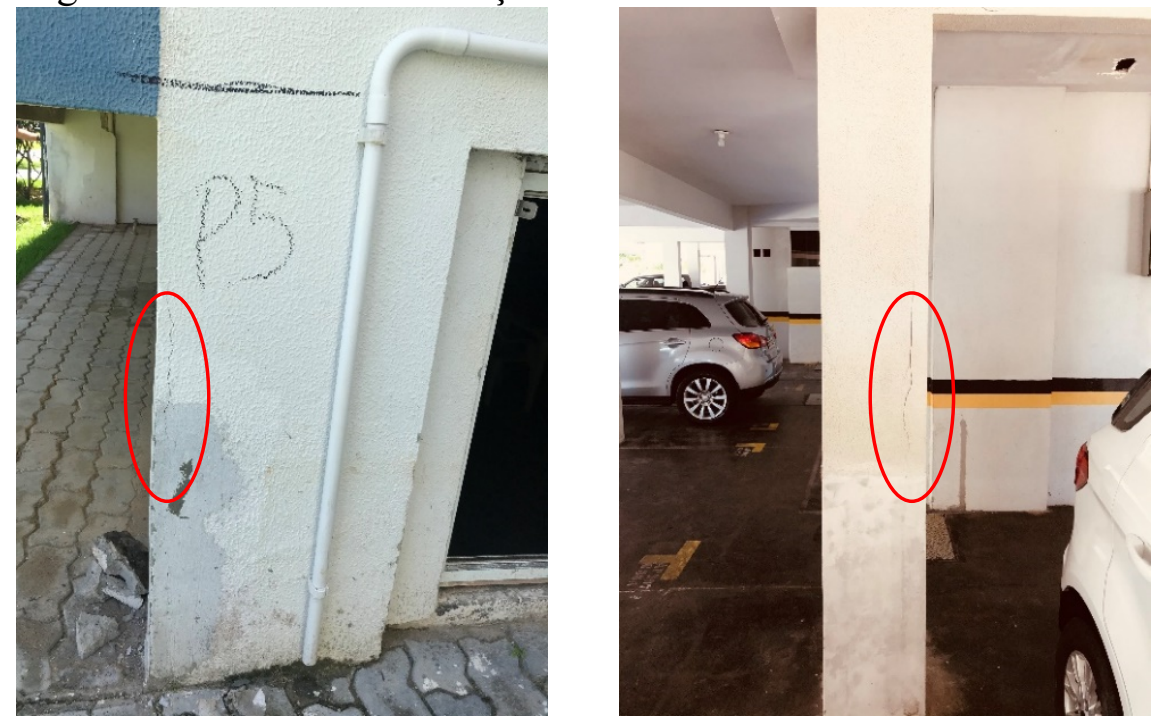

Nota-se que durante o levantamento dos dados, poucos documentos foram obtidos, tornando assim mais lento o avanço dos trabalhos, provocando atraso considerável no processo de inspeção.

Inicialmente foi realizado a avaliação dos projetos de forma (ano de 1994) e arquitetônico (ano de 2008) disponibilizados. Durante essa avaliação foi percebido que eles não convergiam. Dessa forma foi necessário realizar o levantamento dos elementos estruturais dos edifícios para saber qual dos projetos condizia com o encontrado in loco. Essa verificação ocorreu no dia 22/12/2020.

Após a realização da verificação, foi possível desenvolver o croqui dos blocos do condomínio com a locação de cada pilar e viga existente. Tendo em vista o elevado número de elementos a serem analisados iniciou-se a verificação visual dos mesmo e, dessa maneira podendo realizar uma seleção dos elementos estruturais a serem analisados com prioridade. O nível de prioridade se deu de acordo com a integridade estrutural apresentada. 
Devido à falta de projetos estruturais, durante essa primeira etapa foi realizado teste de pacometria para definir a posição das armaduras longitudinais e transversais dos elementos. Durante os ensaios foi possível verificar uma distância significativa entre a armadura e a face dos pilares.

Após análise constatou-se a presença de revestimento argamassado de grande espessura, com acabamento em pintura texturizada. Na parte inferior dos pilares existia revestimento cerâmico, que foram retirados, sendo aplicado nesses locais uma pequena camada de argamassa regularizadora executado com mão de obra própria do condomínio.

Apesar de não ser considerado normativamente para efeitos de cálculo estrutural, o revestimento argamassado, o revestimento cerâmico e a pintura fornecem proteção extra à armadura. Como descrito anteriormente, existe uma camada de espessura considerável de argamassa com pintura texturizada e, até recentemente, existia revestimento cerâmico na base dos pilares.

Foram abertas janelas de inspeção em dois pilares, um íntegro e outro com fissura, para verificação da integridade do concreto. No pilar sem a presença de fissura, com argamassa com IE alto e dificuldade de remoção da textura o concreto não apresentava sinais de deterioração. No outro pilar o concreto apresentava fissuras características de expansão de armadura por corrosão. Observou-se durante as vistorias que os pilares que apresentavam textura perfeita e o revestimento argamassado íntegro dificilmente apresentavam fissuras aparentes visíveis. Numa avaliação expedita utilizou-se o esclerômetro de reflexão na análise do revestimento de argamassa dos pilares, SALIENTA-SE QUE O ESCLERÔMETRO UTILIZADO NÃO É O PRÓPRIO PARA ARGAMASSA E OS RESULTADOS SÃO MERAMENTE COMPARATIVOS.

Nesse ensaio foi retirado somente a camada de textura e feito os testes na argamassa. Após os testes foi verificado que nos pilares sem fissuras aparente a remoção da textura foi muito difícil mesmo com a utilização de esmerilhadeira elétrica e o índice esclerométrico (IE) foi relativamente alto em níveis de IE de concreto (IE-30). Possivelmente esse alto IE seja decorrente do processo de carbonatação que colabora com o endurecimento da argamassa de cimento Portland, em especial na sua superfície. Nos pilares com fissuras a textura soltava facilmente e o IE foi consideravelmente mais baixo ( $\mathrm{IE}<20)$, além disso visivelmente se percebia esfarelamento na argamassa ou presença de umidade.

Figura 4. Janela de inspeção aberta em pilar íntegro (esquerda) e em pilar apresentando fissuras (direita).
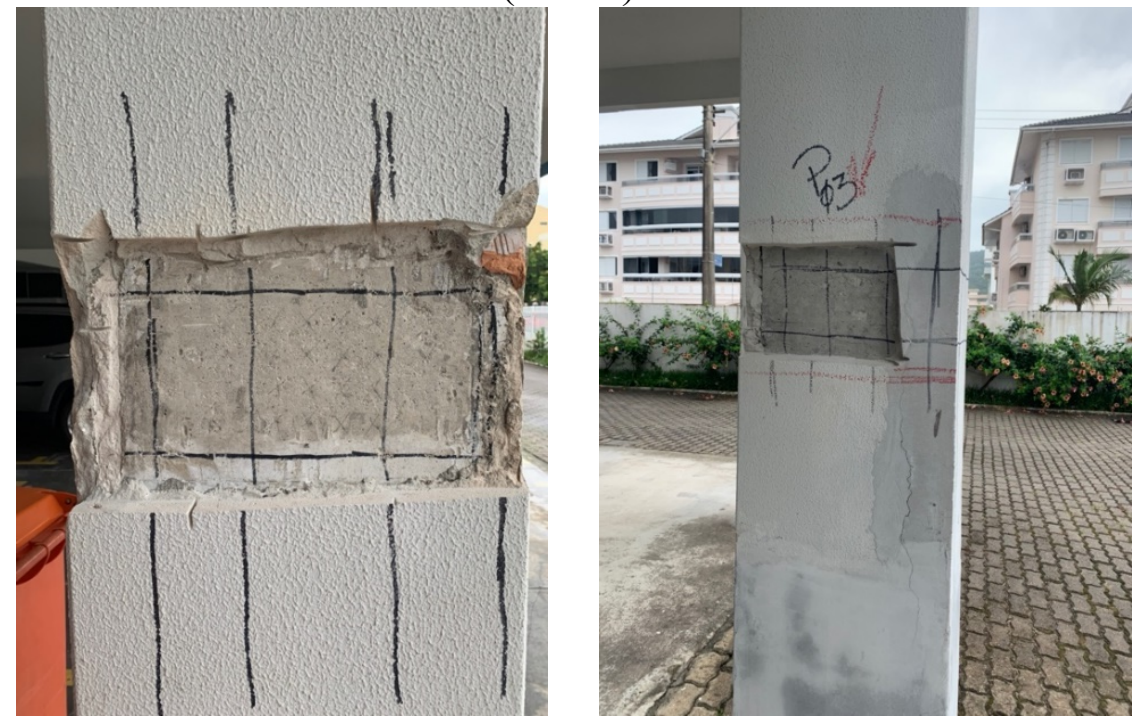

Dessa forma, no dia 30/12/2020 foram os elementos que já apresentam fissuras aparentes devido a expansão das armaduras foram selecionados para serem avaliados primeiramente e, nesses locais 
foram marcados os pontos para a abertura de janelas para vistorias, onde se torna possível acessar as armaduras e avaliar o nível de degradação em que se encontram, além de conseguir complementar as informações construtivas faltantes.

Durante a marcação dos pontos o ensaio à percussão se fez necessário devido a constatação de que muitos pilares tinham incorporado mochetas para passagem de tubulações.

Após a abertura das janelas de inspeções, foi realizada a visita para verificação dos pilares com as janelas de inspeção já executadas e constatou-se que:

$\checkmark$ Diversas fissuras eram decorrentes da ligação entre pilar-mocheta, ou também devido a maior dimensão da própria tubulação dentro da mocheta.

$\checkmark$ Muitas fissuras são decorrentes da expansão de armadura devido à corrosão.

$\checkmark$ Em diversos pilares a corrosão já está em estado avançado, inclusive com perda de seção do aço e desplacamento do concreto. (Figura 05 a)

Figura 5. Corrosão de armadura em estado avançado, apresentando desplacamento do concreto (a) e perda de seção transversal do aço (b) .

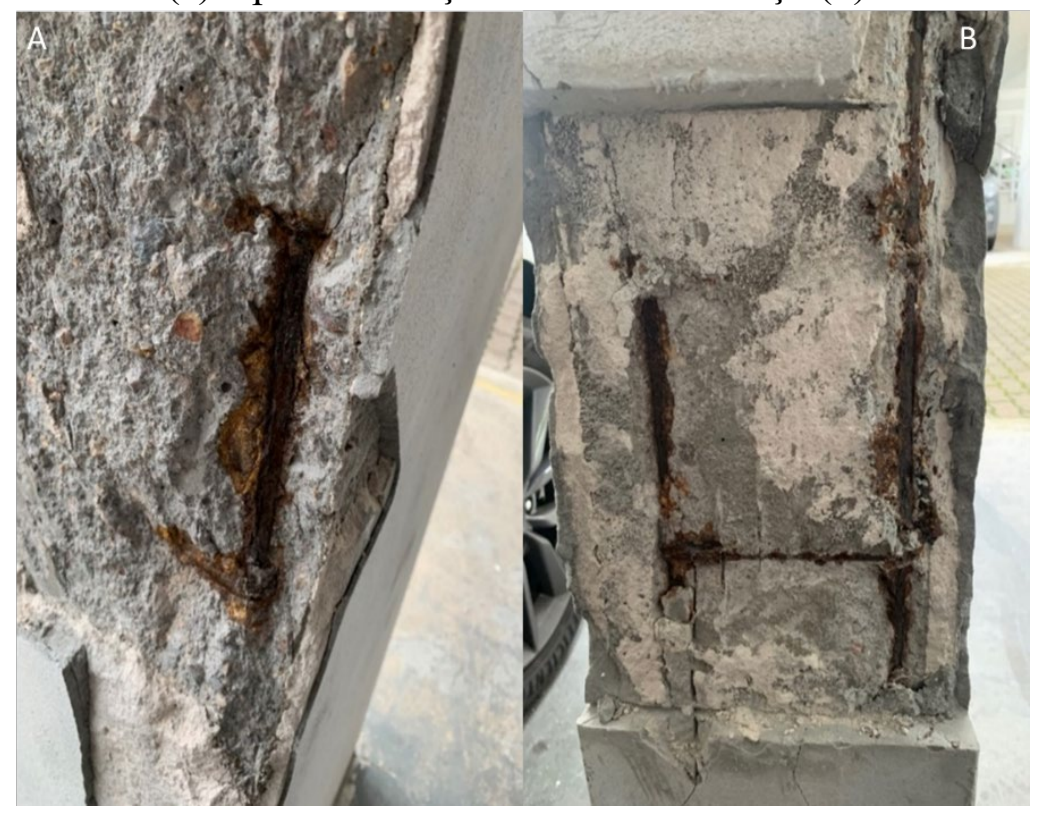

Foram detectadas falhas de execução na recuperação feita em 2016, sendo que diversos pilares que haviam sido recuperados apresentam processo avançado de corrosão da armadura, na região que havia sido recuperada. (Figura $06^{\mathrm{a}}$ e 06b) 
Figura 6. Degradação da área recuperada em 2016, com aplicação de técnicas e materiais não eficiente.

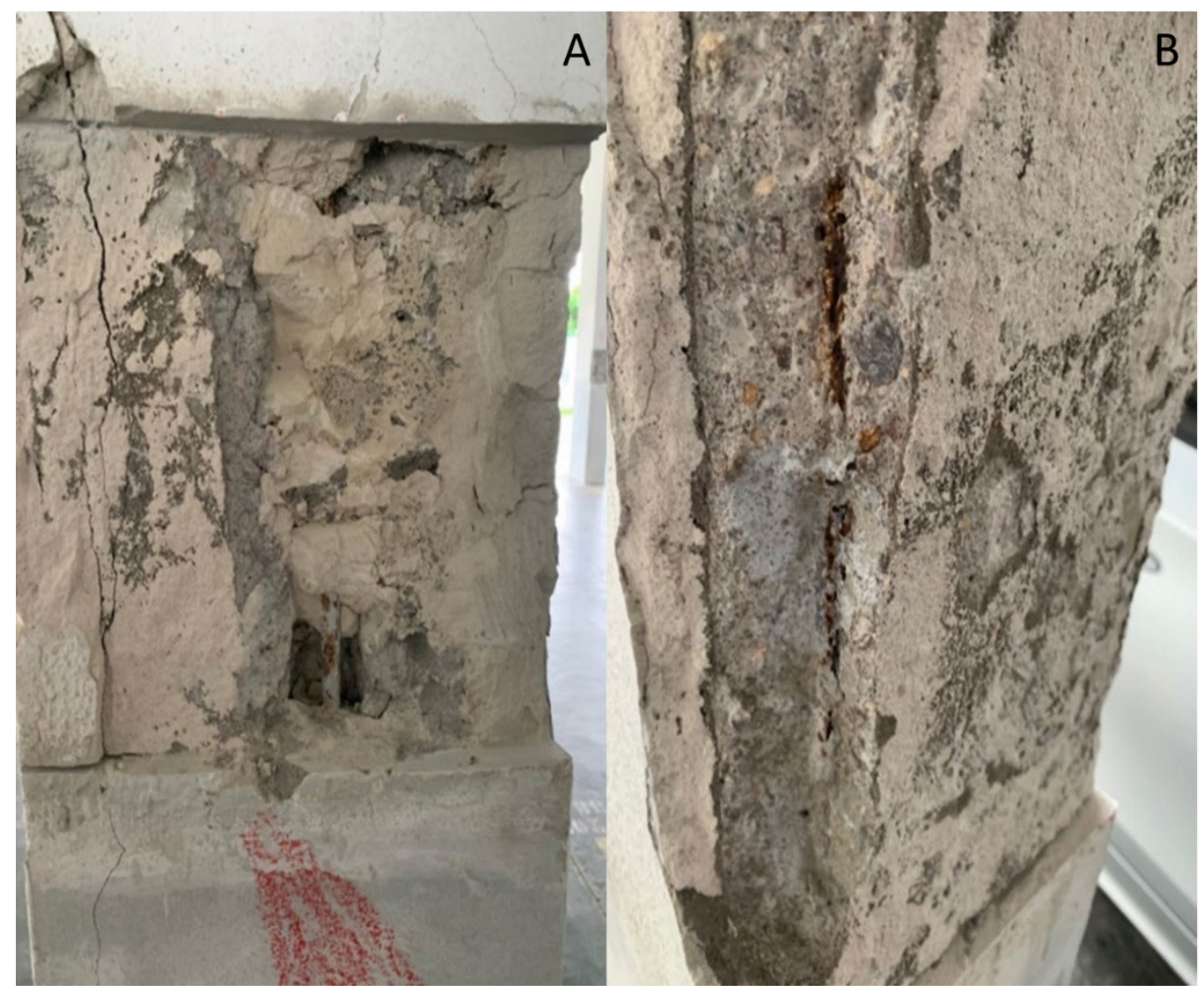

De acordo com o levantamento realizado, constatou-se que os blocos A e B são os que apresentam maior quantidade de pilares em níveis de degradação avançada e, que exigem reparos urgentes. A Figura 07 apresenta o percentual de cada GUT em cada bloco, de acordo com os dados de levantamento. Ressalta-se que no bloco $\mathrm{E}$ apenas um dos pilares apresentou fissuração, porém não apresentando nível avançado, não sendo incluído nesta análise.

Figura 7. Quantidade de GUT em cada bloco vistoriado.

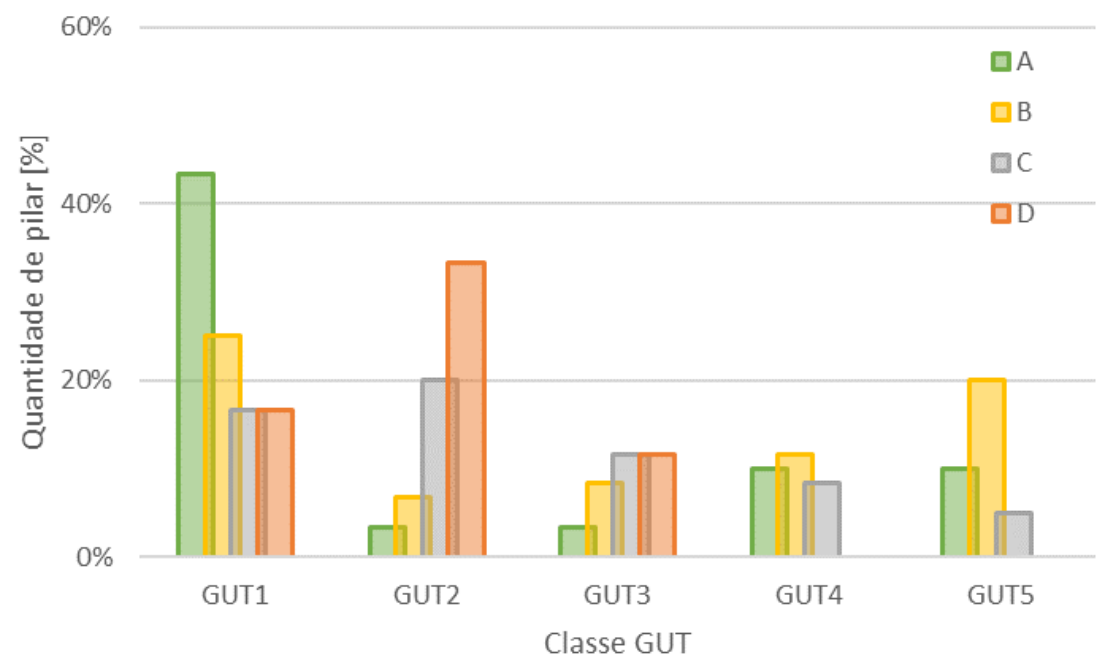


Após o levantamento, é possível verificar que os primeiros blocos que mais de $50 \%$ dos pilares presentes no residencial apresentam alguma manifestação de fissura e, por mais que apenas $7 \%$ se concentre em GUT 5, esses elementos apresentam características de situações que torna o seu tratamento de extrema urgência, considerando toda a problemática envolvida.

Quadro 5. Avaliação global dos GUTs encontrados.
\begin{tabular}{|l|cc|}
\hline GUT & Qtd. & Percentual total \\
\hline GUT1 & 61 & $20,3 \%$ \\
GUT2 & 38 & $12,7 \%$ \\
GUT3 & 21 & $7,0 \%$ \\
GUT4 & 18 & $6,0 \%$ \\
GUT5 & 21 & $7,0 \%$ \\
Sem fissuração & 141 & $47,0 \%$ \\
\hline
\end{tabular}

\section{DIAGNÓSTICO}

Através dos estudos realizados pode-se considerar que a origem das manifestações patológicas observadas nos pilares expostos do pavimento térreo tem sua origem na corrosão das armaduras. Os mecanismos de ocorrência são derivados da penetração de agentes agressivos, em especial o íon cloreto devido a proximidade do mar e ao vento predominante na região que faz com que a estrutura esteja mais tempo exposta a agressividade ambiental.

Aliado a isso cabe salientar que o cobrimento da armadura observado é mínimo, sendo que em alguns pontos não chega a $01 \mathrm{~cm}$, enquanto, por parâmetros atuais o cobrimento nominal da armadura em pilares de concreto armado deve ser de $04 \mathrm{~cm}$ de acordo com a NBR 6118 (ABNT, 2014) onde a classificação geral do tipo de ambiente da edificação é marinha com Classe de agressividade ambiental III, que corresponde a grande risco de deterioração da estrutura.

De acordo com a NBR 12655 (ABNT, 2015) a classe de concreto utilizada em ambientes com classe de agressividade III deve ser maior ou igual a C30 com relação água/cimento menor ou igual a 0,55 . Não foram localizadas maiores informações sobre o concreto que possam atestar a sua qualidade, porém, é fato que o concreto feito em obra dificilmente chegaria a esses parâmetros e no caso de ter sido adquirido concreto em central, historicamente a classe de concreto utilizada na época da construção dos edifícios não passava de C25 que resulta num concreto mais poroso.

Pode-se afirmar que, o cobrimento inadequado ou inexistente da armadura aliado a porosidade do concreto num ambiente marinho de forte agressividade ambiental são os fatores que tem colaborado com o surgimento das manifestações patológicas nos elementos estruturais avaliados. Juntamente com os todos esses efeitos de projeto/execução, a ausência de um plano de manutenção predial adequado corroborou para que a estrutura atingisse um grau de degradação tão elevado.

\section{REFERÊNCIAS}

Associação Brasileira de Normas Técnicas. (2014). NBR 6118: Projeto de estruturas de concreto - Procedimento. Rio de Janeiro. 
ALVES, S. M. A. WWW.PATORREB.COM - Um contributo para a sistematização do conhecimento da patologia

da construção. Faculdade de Engenharia da Universidade do Porto, 2008

Bertolini, L.; elsener, B.; pedeferri, P.; Polder, R. (2004), Corrosion of steel in concrete Prevention, Diagnosis, Repair. Weinhei,, Alemanha: Wiley-VCH.

Bertolini, L. (2010), Materiais de construção: patologia, reabilitação, prevenção. São Paulo, Brasil, p.129.

INSITUTO BRASILEIRO DE AVALIAÇÕES E PERÍCIAS DE ENGENHARIA. (2012), Norma de Inspeção Predial. São Paulo, Disponível em <http://ibape-nacional.com.br/biblioteca/wpcontent/uploads/2012/12/Norma-de-Inspe\%C3\%A7\%C3\%A3o-Predial-IBAPE-Nacional.pdf $>$. Acesso em 29 de Mai 2021.

Neville, A.M. (2016), Propriedades de concreto, 5ed., Porto Alegre, Brasil, p.502.

OLIVEIRA, C. S. P. (2013), Análise Crítica de Experiências e Discussão de Estratégias para Implantação de Leis de Inspeção de Elementos de Fachadas. Tese de Doutorado. Universidade Federal do Rio Grande do Sul. Porto Alegre. 